\title{
Desafios e Procedimentos de TraduçãolTransposiçâo Cultural: Trölo e Créssida e Os Dois Primos Nobres
}

\author{
Challenges and Procedures in Translation and Cultural Transposition: \\ Troilus and Cressida and The Two Noble Kinsmen
}

José Roberto O'Shea

Universidade Federal de Santa Catarina (UFSC)

DOI: https://doi.org/10.5902/2176148561321

Resumo: O presente artigo se vale de ilustrações extraídas de duas traduções em verso e anotadas, de peças teatrais, concluídas pelo autor no âmbito de um projeto apoiado pelo CNPq-PQ. Trata-se de Tróilo e Créssida e Os Dois Primos Nobres, a primeira de autoria de William Shakespeare, a segunda atribuída a Shakespeare e John Fletcher. Para tal, são invocados preceitos da chamada "tradução/transposição cultural” (segundo Sándor e Higgins), bem como noções relativas à tradução de "itens culturais específicos", isto é, “culture-specific items", ou CSIs (segundo Aixelá). $\mathrm{O}$ artigo postula e conclui que tais preceitos podem constituir procedimentos tradutórios básicos, abrangentes, e capazes de enfrentar os notórios desafios lexicais e culturais inerentes à tradução do teatro renascentista inglês.

Palavras-chave: Tróilo e Créssida. Os Dois Primos Nobres. Tradução/transposição cultural.

Abstract: The article resorts to illustrations drawn from two annotated, verse translations of playtexts carried out by the author himself under the aegis of a research project funded by CNPq-PQ. The two plays are Troilus and Cressida and The Two Noble Kinsmen, the former by William Shakespeare and the latter by Shakespeare and John Fletcher. For this purpose, the article invokes precepts of the so-called "translation/cultural transposition" (viz. Sándor and Higgins), as well as notions pertaining to "culture-specific items", or CSIs (viz. Aixelá). The article postulates and concludes that such precepts can become basic, comprehensive translation procedures capable of facing the notorious lexical and cultural challenges inherent to the translation of English Renaissance Drama.

Keywords: Troilus and Cressida. The Two Noble Kinsmen. Translation/cultural transposition. 
"É evidente que traduzir Hamlet

é mais difícil do que escrever o Hamlet.

Fique claro que não quero dizer

mais importante".

Millôr Fernandes

Os desafios decorrentes das complexidades da tradução da poesia dramática shakespeariana têm sido amplamente referidos e comentados. Tais desafios

José Roberto

o'shea resultam tanto de aspectos textuais como contextuais. Dentre os aspectos textuais, destacam-se, e.g., registro e variação linguística, modulações de pronomes de tratamento e pessoa do verbo, ordenação sintática, densidade de imagens e metáforas, malapropismos, trocadilhos e jogo de palavras, sem falar em eufonia, rima e métrica, tampouco no uso e no abuso do pentâmetro iâmbico ${ }^{1}$. Dentre os aspectos contextuais, além do "peso" do "texto clássico", cujo autor já faz parte da cultura de chegada e cuja obra é traduzida e retraduzida, cumpre ressaltar, e.g., itens lexicais absolutamente distantes histórica, geográfica e culturalmente do leitor/espectador brasileiro.

Diante de tais desafios, os procedimentos tradutórios adotados precisam ser bem avaliados e testados. Neste ensaio, recorro a ilustrações extraídas das minhas próprias traduções em verso e anotadas, mais recentemente concluídas no âmbito de um projeto apoiado pelo CNPq. Refiro-me a Tróilo e Créssida e a Os Dois Primos Nobres, esta última de autoria de Shakespeare e John Fletcher. Para tal, eu gostaria de invocar preceitos da chamada "tradução/transposição cultural" (segundo Sándor e Higgins), bem como noções relativas à tradução de "itens culturais específicos", isto é, "culture-specific items", ou CSIs (segundo Aixelá), enquanto procedimentos tradutórios básicos, abrangentes, e capazes de enfrentar os já mencionados desafios.

De início, vale buscar definições operacionais de tradução/transposição cultural e de item cultural específico. Hervey e Higgins definem tradução ou transposição cultural, sucintamente, como "os vários graus de distanciamento em relação à literalidade aos quais se pode recorrer no processo de transferência de conteúdos de um texto-fonte para o contexto da cultura-alvo"2. É certo que a definição parece um tanto vaga. Mas é,

Delabastita, "Shakespeare in Translation" (15-27).

2 Hervey e Higgins, Thinking Translation (28, minhas tradução e ênfase). 
precisamente, o caráter lato senso da definição, além do destaque à noção de contexto, que me agrada. Foi esse distanciamento em relação à literalidade que se mostrou útil na transferência dos textos de Troilus and Cressida e The Two Noble Kinsmen, criados e "consumidos" em Londres nas primeiras décadas do século XVII, para o contexto do Brasil no século XXI.

Quanto à noção de item cultural específico, Aixelá define: “itens lexicais cuja função e conotações no texto-fonte implicam um problema tradutório [...], sempre que tal problema resulte ou da inexistência do referido item, ou de sua condição intertextual distinta no sistema cultural [...] do texto-alvo"'. Aixelá critica a tendência simplista a identificar CSIs com itens relacionados aos aspectos mais arbitrários de qualquer sistema linguístico: instituições locais, nomes de ruas e de figuras históricas, topônimos e nomes próprios, etc. Problematizando a noção de CSI, Aixelá

Desafiose Procedimentos de Tradução/ Transposição Cultural argumenta que se em linguagem tudo é produzido culturalmente, também o serão quaisquer componentes linguísticos e pragmáticos. Portanto, segundo Aixelá, é preciso ampliar o entendimento da definição de CSI, incluindo toda e qualquer referência linguística em um texto-base que ao ser transferida para a língua-alvo apresenta um problema tradutório, como vimos, decorrente ou da inexistência ou do valor diverso que o referido item possui na cultura de chegada. A rigor, essa importante ampliação da definição de CSI permite que qualquer item lexical possa ser considerado um CSI, dependendo de como seria entendido pela cultura de chegada, na medida em que imponha um problema de opacidade ideológica ou cultural, ou mesmo de aceitabilidade para o leitor.

Antes de abordar questões específicas, no entanto, será útil elencar e comentar os principais objetivos do já mencionado projeto tradutório.

1) O primeiro objetivo é realizar uma tradução "literária", isto é, em "linguagem poética", não-ilusionista, teatralizada, acompanhando a importante alternância entre verso e prosa, conforme observada nos textos originários.

Longe de pretender aqui esgotar definições de "literário" e de "linguagem poética", e mesmo de "teatralização", cabe frisar que esse primeiro objetivo visa, sobretudo, atender às questões de registro linguístico, de dicção e de observância da modulação entre verso e pro-

3 Aixelá, "Culture Specific Items in Translation" (58, minhas tradução e ênfase). 
José Roberto

o'shea

144

sa. Quanto ao registro linguístico e à dicção poética, tenho procurado preservar imagens, metáforas, figuras de estilo, inversões sintáticas, bem como um léxico ligeiramente arcaizante, elementos que, aliados a fatores formais - e.g., métrica, eufonias, rimas -- destacam, marcam, a linguagem poética em relação à linguagem prosaica coloquial. Evidentemente, numa tradução de/para teatro, decisões relativas a registro, antes de tudo, seguem as modulações observadas nas falas dos personagens. Portanto, em se tratando de um personagem cuja vivência, formação, ou mesmo cuja situação cênica, seja, por assim dizer, mundana, sua fala não será caracterizada por um registro poético, e, consequentemente, a tradução de tal discurso procura reproduzir padrões locucionais com um registro menos elevado, mais coloquial, conforme será ilustrado nos trechos em prosa aos quais me refiro adiante.

Quanto ao adjetivo "literário", não será exclusividade da poesia, mas também pode se aplicar à prosa. $\mathrm{E}$ todas as peças shakespearianas, à exceção de Rei João e Ricardo II, contêm trechos em prosa. A opção pela tradução em verso (decassílabos brancos ou rimados, na transposição do pentâmetro iâmbico shakespeariano) e prosa (novamente, seguindo a modulação constatada na obra originária) foi estabelecida desde a primeira peça contemplada pelo projeto (Antônio e Cleópatra, 1994-1996). Isso se deu porque na poesia dramática shakespeariana a importante alternância, ou o embate mesmo, entre o verso, com ritmos estruturados, e a prosa, de cadência mais livre, além de demonstrar virtuosismo formal e marcar diferentes estilos de atuação cênica, exerce função dramatúrgica, sublinhando mudanças de tom e atmosfera, propiciando relaxamento de tensão, e servindo para pontuar aspectos temáticos e de caracterização.

É sabido que, de modo geral, temas trágicos, "elevados" (e.g., amor, ódio, vida, morte, honra, valores éticos, bravura, hierarquia), quando tratados por personagens nobres e cultos, aparecem em verso. Por outro lado, temas cômicos ou "chulos" (e.g., obscenidades, vulgaridades, escatologia, patuscadas, palhaçadas, zombarias, loucura, etc.) costumam aparecer em prosa, frequentemente fescenina, e frequentemente enunciada pelos chamados “personagens rústicos". Portanto, se a modulação verso/prosa desempenha funções tão cruciais na construção de temas e personagens nas peças originárias, a meu ver, a tradução deve seguir esse importante gesto técnico.

A título de ilustração, vejamos, primeiro, um trecho em verso -decassílabos brancos, com ictos, preferencialmente, na sexta e na décima sílabas -- concluídos por um dístico. Trata-se, talvez, da fala mais co- 
nhecida da peça Tróilo e Créssida, a dissertação de Ulisses sobre a quebra da hierarquia entre os gregos, fator por ele apontado como responsável pela incapacidade de o exército helênico conquistar Troia, a despeito do cerco que vigora há sete anos (ato 1 , cena 3 ):

Troia, inda de pé, já teria caído,

E a espada do grande Heitor sem dono

Desafiose

Já estaria, não fossem estas causas:

Procedimentos

A práxis do poder foi desprezada, de Tradução/

E vede quantas tendas gregas jazem Transposição

Vazias no campo; são vazias facções.

Cultural

Quando o general não é a colmeia

À qual as abelhas vêm convergir,

Que mel pode esperar-se? A hierarquia

Estando mascarada, os indignos

Com máscara se mostram muito belos.

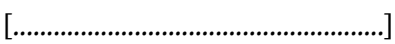

[...] Ah! Quando a hierarquia

É sacudida, sendo ela a escada

De acesso aos desígnios mais altos,

A investida enfraquece. Como haver

Comunidade, escola, associação,

Comércio e paz entre praias distantes,

Direito a berço e primogenitura,

Respeito à idade, cetro, coroa, louros,

Se a hierarquia sair do seu lugar?

Tirai a hierarquia, desafinai-a,

E ouvi a confusão: todas as coisas

Caem em total conflito; a água contida

Eleva acima do limite o nível

E transforma em papa a terra firme;

o forte prevalece sobre o fraco,

E o filho bruto ataca e mata o pai;

Força vira lei; isto é, certo e errado,

Cujo embate é a casa da justiça,

Com a própria justiça se confundem;

Então, tudo à força se resume,

Força à vontade, vontade à ganância, 
E a ganância, o lobo universal,

Apoiada p'la força e p'la vontade,

Cria, então, uma presa universal

E acaba devorando-se a si mesma.

Grande Agamenon,

O caos, se a hierarquia é sufocada,

Segue a comilança;

E o desprezo à ordem faz descer,

Passo a passo, quando o intento é subir.

José Roberto

o'shea

146 o líder é enjeitado pelo abaixo,

Este pelo seguinte, o seguinte

Pelo que vem abaixo... Cada passo,

A exemplo do primeiro, a desprezar

Seu superior, cede à febre invejosa

Da pálida e cruel rivalidade;

É a febre que mantém Troia de pé,

Não a potência. Venho aqui expor:

Troia é nossa fraqueza, não é vigor.

O conteúdo "tematicamente elevado" do trecho é ressaltado pela rigidez formal do verso e pela dicção artificiosa que caracteriza o registro poético.

Vejamos um exemplo, agora, de verso metrificado em Os Dois Primos Nobres. Trata-se da primeira grande fala de Teseu, na primeira cena do primeiro ato, quando ele, Duque de Atenas, que naquele mesmo dia se casava com Hipólita, Rainha das Amazonas, responde à primeira das três rainhas que lhe rogam o direito de incinerar os corpos dos esposos mortos por Creonte, corpos que agora jazem insepultos nos campos de Tebas:

TESEU

Não vos ajoelheis, é o que vos peço.

Com as vossas palavras me espantei,

E deixei que os joelhos vos magoassem.

Ouvi sobre a sorte dos vossos mortos,

O que me causa muita pena, e em mim

Desperta o desejo de vingança.

O rei Capaneu era vosso esposo.

No dia das bodas, como hoje comigo, 
No altar de Marte vi o vosso noivo.

Éreis naquele tempo muito bela -

Não era o véu de Juno mais formoso

Que os vossos cabelos, nem tão vasto.

Vossa coroa de trigo não estava

Debulhada, tampouco destruída.

A Fortuna, de covinhas no rosto,

Desafiose

Para vós sorria. Hércules, meu primo,

Cedendo ao vosso olhar, depôs a clava;

Procedimentos

Desabou sobre a pele de Neméia,

de Tradução/

E jurou que seus músculos se esvaíam.

Transposição

Cultural

ó dor e tempo! Tudo devorais!

Novamente, a gravidade da situação e a condição social dos interlocutores - um duque dirigindo-se a uma rainha - requerem a formalidade e a dicção estilizada do verso metrificado.

Em contrapartida, vejamos o bate-boca entre Pátroclo e Tersites, na primeira cena do quinto e último ato de Tróilo e Créssida, em que o conteúdo escatológico e vulgar é expresso em prosa:

\author{
PÁTROCLO \\ Quem vai cuidar da tenda? [de Aquiles, que vai deixá-la, para \\ lutar com Heitor] \\ TERSITES \\ Ora! Qualquer médico... \\ PÁTROCLO \\ Parabéns, espírito de porco! E qual é a necessidade das piadi- \\ nhas? \\ TERSITES \\ Cala a boca, menino! Não lucro com a tua conversa fiada. Dizem \\ que és o garoto de Aquiles. \\ PÁTROCLO \\ Garoto, canalha, como assim? \\ TERSITES \\ Ora! O prostituto dele! Agora, que doenças venéreas, nós nas tri- \\ pas, hérnias, catarros, pedras nos rins, pasmaceiras, paralisias, \\ olhos remelentos, podridão no fígado, assovio nos pulmões, ab- \\ cesso na bexiga, ciáticas, suores e calores, dores nos ossos e eter-
}


nos eczemas se abatam, muitas e muitas vezes, sobre essa putaria.

\section{PÁTROCLO}

Ora! Maldito poço de inveja! o que pretendes rogando tantas pragas?

\section{TERSITES}

Enfiaste a carapuça?

\section{PÁTROCLO}

Ora! Não, barrica podre, cão disforme, filho-da-puta, não!

José Roberto

o'shea

148

E vejamos, agora, em Os Dois Primos Nobres, o momento em prosa, na terceira cena do quarto ato, no qual entra a fascinante Filha do Carcereiro, figura que não consta em Chaucer (fonte principal da peça), sendo, portanto, criação de Shakespeare e Fletcher (geralmente atribuída a Shakespeare). A jovem, enlouquecida pelo amor não-correspondido de Palamon, e recém-resgatada de um afogamento pelo Pretendente, sente-se no inferno de Hades:

MÉDICO

Que lindo o delírio dela! Vamos ouvi-la um pouco mais. FILHA

Eu vos digo: às vezes, brincamos de pega-pega, nós, as abençoadas. Ai! É triste a vida lá no outro lugar -- queimam, fritam, fervem, silvam, uivam, tiritam, praguejam. Ah, é severo o castigo deles, cuidado! Quem fica louco, se enforca ou se afoga, vai direto pra lá - valei-nos Júpiter! - e lá eles metem a gente num caldeirão cheio de chumbo derretido e banha de agiota, no meio de um milhão de punguistas, e lá a gente cozinha como um pernil de porco que nunca fica pronto.

MÉDICO

Como a mente dela fantasia! FILHA

Lordes e cortesãos que engravidam as criadas vão direto pra lá. São metidos no fogo até o umbigo, e no gelo até o coração, e lá a parte que ofendeu queima, e a parte que enganou congela; na verdade, é um castigo cruel demais, alguém pode pensar, por uma coisinha de nada. Podeis acreditar no que digo: esses homens se casariam com uma bruxa leprosa, pra se livrarem daquilo - eu garanto. 
MÉDICO

Como prossegue no delírio! Não é loucura, mas uma intensa e profunda melancolia.

FILHA

Ouvir uma nobre orgulhosa e uma burguesa orgulhosa uivarem lado a lado - eu seria um monstro se dissesse que é divertido. Uma grita “Ah... esta fumaça!"; “Este fogo!” grita a outra; uma grita “Ah... por que fui fazer aquilo atrás da cortina!”, e depois uiva; a outra amaldiçoa um sujeito sedutor e o caramanchão.

Assim como, na quinta cena do quarto ato de Hamlet, Ofélia, enlouquecida, entra e se expressa em prosa, aqui, a Filha do Carcereiro também se vale da prosa para extravasar o delírio de seu amor frustrado.

Desafiose

Procedimentos

de Tradução/

Transposição

Cultural

2) O segundo objetivo do projeto é produzir um texto encenável, enunciável e compreensível, sem ser desnecessariamente domesticado.

Se tanto quanto a escritura originária de/para teatro, a tradução de/para teatro deve procurar reproduzir padrões de fala, é crucial que o texto teatral - novamente, originário ou traduzido - seja encenável, enunciável e compreensível. Já se tem escrito sobre a "encenabilidade" ("falabilidade") e acessibilidade do texto teatral, e tais preocupações não podem deixar de pautar o trabalho do(a) tradutor(a) teatral ${ }^{4}$. Assim, o segundo objetivo do projeto visa à construção de um texto capaz de ser oralizado, no palco, com certa "naturalidade", mas sem, ao mesmo tempo, ser linguisticamente facilitado, eu diria, trivializado.

3) O terceiro objetivo é realizar a já mencionada anotação, que abranja aspectos de texto, contexto, encenação e tradução.

Considerando que meu projeto tradutório contempla paratextos (ensaios e notas, além de bibliografia selecionada), um espaço que acomoda glosas, numa manipulação intercultural que visa esclarecer questões de texto, contexto, encenação e tradução, a cabível preocupação com "encenabilidade" e acessibilidade não implica a inserção de simplificações, de domesticação, no texto em si. A exemplo dos seis projetos conclu-

4 Ver Bassnett, Totzeva, Marinetti. 
José Roberto

o'shea

150

ídos anteriormente, a anotação de Tróilo e Créssida e Os Dois Primos Nobres abrange aspectos textuais, i.e., elucidação não apenas de problemas relacionados a impasses textuais atinentes à complexa fixação do texto dramático shakespeariano, como de questões lexicais e/ou frasais afetas aos primórdios da língua inglesa na modernidade. A anotação trata, também, de questões contextuais, i.e., esclarecendo referências históricas e/ou culturais, explicando fatores pertinentes ao teatro e ao "mundo shakespeariano", de vez que, a despeito do tempo e lugar da ação, as peças sempre se inserem no contexto londrino da virada do século XVI.

A anotação trata, ainda, de questões de encenação, incluindo comentários acerca de determinadas soluções cênicas adotadas por determinadas montagens, sobretudo no caso de momentos de encenação reconhecidamente complexa. $\mathrm{E}$, finalmente, trata de questões de tradução, propriamente, oferecendo comentários sobre soluções tradutórias, nesses casos, sempre registrando a formulação linguística constante da peça originária. 0 objetivo geral do paratexto continua sendo o de intensificar a fruição das experiências de leitura e preparação da encenação.

Retomando a noção de "tradução (ou transposição) cultural”, eu diria que, se Millôr Fernandes está certo - e traduzir Hamlet é mais difícil do que escrever Hamlet --, na minha prática, estratégias de tradução cultural, sobretudo quanto aos chamados "itens culturais específicos", têm se mostrado úteis. Valendo-me do "distanciamento em relação à literalidade", sancionado pela já citada definição lato sensu de "tradução cultural", eu destacaria, a título de ilustração, a estratégia relativa à tradução da alternância de pronomes de tratamento e respectivas pessoas do verbo. No artigo “'Thou' and 'You' in Shakespeare: A Study in the Second Person Pronoun", J. Mulholland estabelece que, em Shakespeare, a rigor, a importante alternância dos pronomes pessoais thou e you, dos pronomes objetivos thee e you e dos pronomes possessivos thine e your, denota, respectivamente, informalidade (ou intimidade) e formalidade (ou reverência).

Ora, na tradução, em teoria, bastaria seguir tal modulação, junto às respectivas formas verbais. No entanto, na prática, isso não foi possível. Em diversas situações, e.g., diálogos entre Pândaro e Créssida (tio e sobrinha) e Tróilo e Créssida (amantes), ou Palamon e Arcite (primos nobres), a tradução se distancia da obra originária, em que os pronomes costumam ser you e your, e prioriza a segunda pessoa do singular, nas 
formas tu/teu, pois o emprego dos pronomes vós/vossos, nesses casos, além de soar artificial, denota uma formalidade culturalmente estranha ao contexto brasileiro da transposição.

Vejamos alguns exemplos. Brevemente, o primeiro (ato 1, cena 2) integra um diálogo entre Pândaro e Créssida, em que o tio alcoviteiro tenta "vender" para a sobrinha a imagem de Tróilo:

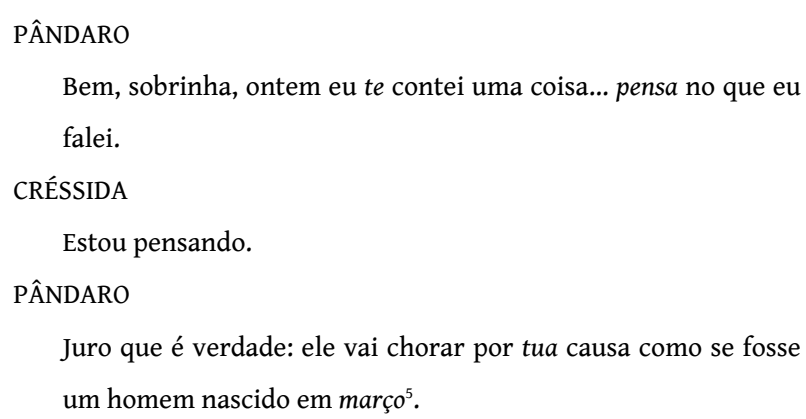

Nesse breve exemplo, é possível perceber que a tradução se afasta duplamente do literal. Primeiro, quanto ao uso da segunda pessoa do singular, quando a obra originária emprega a segunda pessoa do plural; e, também, ao substituir April, que na tradição inglesa, além de ser o mês lírico, das flores e da primavera (basta lembrar o primeiro verso de The Waste Land: "April is the cruellest month"), é o mês mais chuvoso, por "março", no contexto cultural brasileiro, o mês "das águas". Esse tipo de manipulação intercultural é, precisamente, a estratégia que me pareceu benéfica.

Vejamos, agora, um exemplo de afastamento em relação ao emprego de pessoa do verbo e da forma verbal retirado de Os Dois Primos Nobres. Trata-se da segunda cena do segundo ato, quando Palamon e Arcite, trancafiados na mesma cela, trocam juras de eterna amizade:

\author{
PALAMON \\ Como vais, primo nobre? \\ ARCITE \\ E tu, como estás? \\ PALAMON \\ Ora! Forte bastante para rir
}

5 As itálicas em todos os exemplos são minhas. 
Do azar e arcar co' as surpresas da guerra;

Porém, receio, primo, que p'ra sempre

Seremos prisioneiros.



ARCITE

Tenhamos a prisão por santuário

Que nos livra da corrupção dos vis.

Somos jovens e a via da honra buscamos.

[.......................................................]

José Roberto

Que bênçãos dignas podem existir

Das quais as nossas imaginações

Não possam se apropriar? Juntos, aqui,

Somos u'a mina infinda, um para o outro;

Somos esposos, cujo afeto sempre

Renasce; somos pais, amigos, sócios;

Um a família do outro; sou teu herdeiro,

E tués o meu.

[..

Talvez eu caísse doente, primo,

Onde não soubesses, e perecesse

Sem tuas nobres mãos cerrando-me os olhos,

Sem tuas preces aos deuses. Mil acasos,

Nos apartariam, nós aqui não estando.

PALAMON

Tu me deixaste - grato primo Arcite -

Quase enamorado do cativeiro.

Que infelicidade é viver lá fora!

Digo mais?

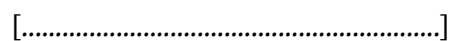

ARCITE

Quero ouvir-te.

PALAMON

Vais ouvir.

Terá existido dois que mais se estimem

Do que nós, Arcite?

ARCITE

Certo que não. 


\section{PALAMON}

Não creio que a nossa amizade um dia

Nos abandone.

ARCITE

Até morrermos, não.

Considerando a intimidade existente entre os dois primos nobres, seria incongruente mantê-los se tratando na segunda pessoa do Desafiose Procedimentos plural, conforme ocorre na peça originária. Além disso, o tratamento de Tradução/ $t u$, ao reforçar essa mesma intimidade, acentua a arrasadora ironia do Transposição rompimento que ocorre imediatamente a seguir, quando, Palamon, priCultural meiro, e, logo depois, Arcite veem Emília, irmã de Hipólita, passeando no jardim da prisão. Ambos se apaixonam pela jovem, à primeira vista, e o conflito da peça é instalado.

De volta a Tróilo e Créssida, vejamos outros três exemplos de distanciamento em relação ao literal, agora, não mais envolvendo modulação de pessoa do verbo, mas transposição cultural, pura e simplesmente. 0 primeiro ocorre no mesmo ato 4, cena 2, quando em um diálogo com o tio, Créssida afirma - em vão, obviamente -- que não irá para o lado dos gregos:



Ocorre que o texto originário registra "crown". Ora, no contexto cultural brasileiro seria inviável traduzir: "Tornai o nome Créssida a coroa / Da falsidade", visto que para o leitor/espectador brasileiro o item cultural específico "coroa" conota, segundo o Dicionário Aurélio: "Bras. Gír. Pessoa idosa em relação a quem fala". Créssida pode ser falsa, mas é também jovem.

O segundo exemplo de formulação que adquire valor de item cultural específico se refere à segunda cena do quinto ato, quando Tróilo, Ulisses e Tersites espionam o furtivo encontro entre Créssida e Diomedes. 
ULISSES

Fiquemos onde a tocha não nos mostre.

[Entra Créssida]

TRÓILO

Vem Créssida encontrá-lo.

DIOMEDES

Então, como estais, minha prisioneira?

CRÉSSIDA

Ah, meu meigo guardião, u'a palavrinha.

José Roberto

o'shea

154

[Sussurra algo a Diomedes]

TRÓILO

Tão íntimos?

ULISSES

Ela é capaz de encantar qualquer homem

Logo à primeira vista.

TERSITES

E qualquer homem pode cantá-la, desde que se aposse de sua clave: ela é digna de nota.

No texto originário, Ulisses diz: "She will sing any man at first sight". Dada a sutileza do sentido duplo do comentário do polido Ulisses, a tradução literal de "sing" pelo grosseiro "cantar" seria uma banalização. Portanto, "encantar" parece ser uma opção culturalmente mais aceitável -- além da feliz aproximação sonora com "cantar”. Já a resposta do cínico e desbocado Tersites - "And any man may sing her, if he can take her clef: she's noted" --, permite o uso de "cantar", em duplo sentido, mesmo porque clef (clave) significava, também, "vagina”. E fica, ainda, preservado o duplo sentido de Créssida ser "digna de nota", isto é, tanto no campo semântico "musical", digna de ser louvada em versos, como no sentido de "notória, famosa", na difamação de Tersites.

Ainda em Tróilo e Créssida, temos um exemplo de mediação cultural que não diz respeito à tradução, em si, mas à revisão da redação da breve nota apensa a Deífobo, na lista de personagens que precede o texto da peça. A referida revisão envolveu a substituição de um item considerado "demasiado forte", ou talvez inaceitável, por algo mais "brando", ou que, supostamente, possa ser aceito pelo leitor ${ }^{6}$. Na pri-

6 Aixela', 64 
meira versão da tradução, a referida nota assim identificava Deífobo: "Na mitologia grega, príncipe de Troia, filho de Príamo e Hécuba. Com a morte de Páris, acaba ficando com Helena". Evitando o duplo sentido da expressão "ficar com", na revisão, optei por "une-se a Helena".

Vejamos, então, alguns exemplos de mediação cultural em Os Dois Primos Nobres. Na terceira cena do segundo ato, entram quatro camponeses, a caminho dos jogos organizados pelo Duque Teseu. Quando o Primeiro Camponês, referindo-se à reação da esposa ao sabê-lo ausente, afirma "I am sure to have my wife as jealous as a turkey", a tradução modula: "Tenho certeza que minha esposa vai ficar ciumenta como uma pavoa". Ocorre que o literal -- "perua" -- será opção culturalmente estranha, o item significando, novamente, segundo o Dicionário Aurélio: "Bras. Mulher de aparência e comportamento exagerados".

Desafiose Procedimentos de Tradução/ Transposição Cultural ro diz: "He's excellent in the woods; bring him to th' plains, his learning makes no cry". A opção tradutória implicou mais um afastamento do sentido estrito: "No bosque ele é excelente; levai-o pra o campo aberto, e seu saber se cala". Na situação de enunciação, dizer "levai-o pra campinas" haveria de gerar estranhamento cultural, de vez que, para o espectador brasileiro, Campinas é cidade do interior do estado de São Paulo.

Finalmente, na primeira cena do terceiro ato, Arcite, referindo-se ao iminente e nobre duelo entre os dois primos, diz: "I am persuaded this question, sick between's, / By bleeding must be cured". Fez-se necessária mais intermediação cultural: "Estou convencido / De que essa questão, qual uma doença, / Só será curada com sangramento", pois "sangria" será, também, "Bebida refrigerante preparada com vinho, água, açúcar, suco de limão, e pedaços de frutas, em especial laranja e maçã" (Aurélio). Não que o mal que afeta os dois primos nobres não pudesse ser curado com uma bela farra, mas não parece ser esse o caso.

Eu penso que poderia aduzir outros exemplos, mas, não escrevo em verso, e a prosa já vai longe. Espero que essas ilustrações tenham bastado para explicar como os preceitos da "tradução/transposição cultural", bem como a ampliação da ideia de item cultural específico, ensejaram uma estratégia tradutória básica, abrangente, e capaz de auxiliar no enfrentamento dos desafios inerentes à transposição da poesia dramática shakespeariana. 


\section{REFERÊNCIAS}

AIXELÁ, Javier Franco. "Culture Specific Items in Translation". Translation, Power, Subversion. Eds. Román Álvarez \& Carmen-África Vidal. Topics in Translation 8. Clevendon: Multilingual Matters Ltd., 1996. 52-78.

BASSNETT, Susan. "Translating for the Theatre: The Case Against Performability”. Traduction, Terminologie, Redaction. Montreal: University of Montreal Press, 1991. 99-111.

o'shea

DELABASTITA, Dirk. “Shakespeare in Translation: A Bird's Eye View of Problems and Perspectives". Accents Now Known: Shakespeare's Drama in Translation. Ed. José Roberto O'Shea. Ilha do Desterro 36.1 (1999): 15-27.

FERNANDES, Millôr. "Sobre a Tradução". William Shakespeare: A Megera Domada. Porto Alegre: L\&PM, 2010.

MARINETTI, Cristina. "The Limits of the Play Text: Translating Comedy". New Voices in Translation Studies 1 (2005): 31-42.

PARRA, Nicanor. Lear Rey \& Mendigo. Santiago: Ediciones Universidad Diego Portales, 2004.

HERVEY, Sándor \& Ian Higgins. Thinking Translation: A Course in Translation Method, French to English. London: Routledge, 1992.

HONAN, Park. Shakespeare, a Life. Oxford: Oxford University Press, 1998.

MCDONALD, Russ. "Here Follows Prose". Shakespeare and the Arts of Language. Oxford Shakespeare Topics. Oxford: Oxford University Press, 2001. 108-36.

MULHOLLAND, J. “'Thou' and 'You' in Shakespeare: A Study in the Second Person Pronoun”. English Studies 48 (1967): 34-43. 
TOTZEVA, Sophia. "Realizing Theatrical Potential: The Dramatic Text in Performance and Translation". The Practices of Literary Translation: Constraints and Creativity. Eds. Jean Boase-Beier \& Michael Holman. Manchester: St. Jerome, 1999. 81-90.

VICKERS, Brian. The Artistry of Shakespeare' Prose. London: Routledge, 2005.

Desafiose

Procedimentos

de Tradução/

Transposição

Cultural

157 
